\title{
Job Choice and Post Decision Dissonancel
}

\author{
EdWard E. LAWLer III \\ University of Michigan \\ WAlter J. Kuleck, JR. \\ University of Michigan \\ John Grant Rhode \\ University of Washington
}

AND

JAMES E. SORENSEN

University of Denver

The job choice and post decision attitudes and behavior of 431 accounting students were studied. Data on the attractiveness of working for different firms was shown to be a good predictor of both the job application and the job choice behavior of the individuals. Data collected after the job choice decision was made showed that the chosen firms increased in attractiveness after choice and the rejected firms decreased. After one year of employment, the subjects rated all firms lower in attractiveness than they had before they applied for jobs. It was concluded that attitudes toward firm attractiveness determine job choice behavior and that job choice behavior influences post employment attitudes about firm attractiveness.

Considerable information exists about the personal characteristics of individuals who choose different occupations and jobs (see Super, 1957; Super \& Bohn, 1970 for a review). There is, for example, research on the kind of interest and ability patterns which are characteristic of indi-

${ }^{1}$ This study is sponsored jointly by the American Institute of CPAs and nine of the large CPA firms. Listed alphabetically these firms are: Arthur Andersen \& Co.; Coopers \& Lybrand; Haskins \& Sells; Laventhol Krekstein Horwath \& Horwath; Main Lafrentz \& Co.; Peat, Marwick, Mitchell \& Co.; Price Waterhouse \& Co.; Touche Ross \& Co.; and Arthur Young \& Company. A commission, comprised of representatives of AICPA and CPA firms participating financially in the project, meets periodically with the researchers to serve in an advisory capacity and to appraise the progress of the study for the purpose of approving the continuation of financial support. The analysis and interpretations are those of the researchers and do not necessarily represent those of the commission or the sponsoring firms. The authors would also like to thank Jeffrey L. Harkins for his help with the project. 
viduals who occupy different occupations. Research on the psychological dynamics of the job choice decision is almost entirely missing, however. Consequently, little is known about how individuals go about deciding which jobs to apply for and which jobs to take.

Studies which have taken an expectancy theory approach to job choice do provide some evidence on the kind of psychological processes which operate. A number of studies (Holstron \& Beech, 1973; Mitchell \& Knudsen, 1973; Sheard, 1970; Vroom, 1966; Wanous, 1972) have shown that the attractiveness of an occupation is determined by the rewards it is perceived to offer and the attractiveness of these rewards. Vroom (1966) has also shown that students will actually choose the job which they perceive has the greatest probability of leading to outcomes that they desire. Thus, there is some evidence which suggests that expectancy theory can be used to understand job choice. However, only the Vroom study has actually looked at job choice, and it was done on a small sample of Masters degree students at one university. No study has used expectancy theory to analyze which jobs individuals apply for and then has gone on to study their actual job choice decision and their initial reactions to their jobs.

A number of individuals have contributed to the theoretical development of expectancy theory (see Atkinson, 1964; Lawler, 1973 for a review). Although differences exist among the many expectancy theories which have been developed, they are largely differences in terminology that do not lead to different predictions with respect to the job choice situation. They all are cognitive motivation theories that specify what determines the choices individuals make. Further, all argue that in making choices among alternative behaviors individuals consider both the likelihood that certain outcomes will result from the behaviors and the attractiveness of the outcomes. The prediction is that individuals will choose to behave in the way which is expected to produce the most attractive combination of outcomes.

Lawler (1973) has recently applied expectancy theory to the job choice situation and has stressed the distinction between two different kinds of expectancies. The first (Effort $\rightarrow$ Performance) expectancy refers to the probability that a person can perform the intended behavior, in this case obtain the job. The second (Performance $\rightarrow$ Outcome) refers to the probability that certain outcomes will result from the intended behavior, in this case obtain high pay, personal growth, etc., from holding the job. The outcomes which result from successful performance are assumed to vary in attractiveness as well as in the degree to which they are likely to be obtained. The theory suggests that the attractiveness of a behavior is influenced by both the attractiveness of the outcomes and the probability the outcomes will be obtained. According to 
the theory, Performance $\rightarrow$ Outcome $(\mathrm{P} \rightarrow \mathrm{O})$ probabilities should be multiplied by the attractiveness or Valence (V) of each outcome and then the products should be summed in order to determine the attractiveness of a behavior. Thus,

$$
\text { Attractiveness of Behavior }=\Sigma[(\mathrm{P} \rightarrow \mathrm{O})(\mathrm{V})] .
$$

In order for behavior to predicted, however, the first or Effort $\rightarrow$ Performance $(E \rightarrow P)$ expectancy must also be considered since according to the theory individuals avoid behavior which they feel is beyond their ability to perform. The final step in the expectancy model, therefore, calls for combining the $\mathrm{E} \rightarrow \mathrm{P}$ expectancy with the attractiveness of the behavior. Thus,

Motivation to Perform the Behavior

$$
=(\mathrm{E} \rightarrow \mathrm{P}) \text { (Attractiveness of Behavior). }
$$

The final prediction of the theory is that in a choice situation individuals will perform the behavior which yields the highest score when attractiveness and $\mathrm{E} \rightarrow \mathrm{P}$ are combined.

Figure 1 illustrates the sequence which this approach suggests an individual might go through in picking a job. It shows a person beginning by searching the environment for possible jobs. Once a number of jobs have been identified, the individual selects some to apply for based upon the probability that they can be obtained and their attractiveness. Application is then made for some of the jobs, job offers received from some number of them and finally, the most attractive firm making an offer is chosen. If this approach is correct, then the job choice behavior of individuals should be predicted by their $\mathrm{P} \rightarrow \mathrm{O}$ and $\mathrm{V}$ attitudes. It is less clear, however, how $\mathrm{E} \rightarrow \mathrm{P}, \mathrm{P} \rightarrow \mathrm{O}$ and $\mathrm{V}$ attitudes can be used to predict job application behavior. Several complications make it unlikely that a good prediction of interview behavior can be obtained by determining which jobs have the highest $(\mathrm{E} \rightarrow \mathrm{P})$ (Job Attractiveness) scores.

Students are often encouraged to apply for jobs so they can learn how to interview and they are also encouraged to apply for a wide range of jobs to "see how they can do in the job market." Further in most situations individuals can apply for a number of jobs and they don't have to choose between applying for one job or another. This point is important because expectancy theory is concerned with how people choose among

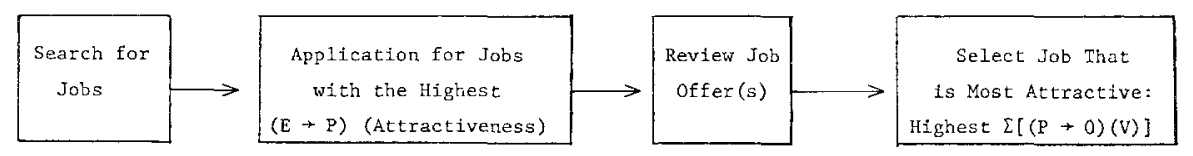

Figure 1 
mutually exclusive alternative behaviors. Thus, although there is reason to believe that $\mathrm{E} \rightarrow \mathrm{P}, \mathrm{P} \rightarrow \mathrm{O}$ or $\mathrm{V}$ attitudes about jobs may predict job application behavior, it is not clear that by themselves they should do a good job predicting it.

Although expectancy theory makes no prediction about how actually making the choice of a job will affect its attractiveness and the attractiveness of other firms, several theories do. Dissonance theory predicts that the selected job should become more attractive in comparison to the rejected ones (Festinger, 1957). The opposite prediction is suggested by the research on regret (Walster, 1964).

A number of studies have looked at the relationships between seniority and job attractiveness and have usually found that it decreases during the early years of employment (Vroom, 1964; Vroom \& Deci, 1971). Yet only one study (Vroom, 1966; Vroom \& Deci, 1971) has directly measured the effects of job choice decisions on the attractiveness of both the selected job and the rejected job(s). The evidence seems to support the dissonance theory prediction. Research on the determinants of job attractiveness has obvious implications for understanding employee membership behavior as well as for understanding and developing expectancy theory and job satisfaction theory. With respect to expectancy theory, for example, research can contribute to the understanding of what influences the development of such components of the model as $\mathrm{P} \rightarrow \mathrm{O}$ expectancies and the attractiveness of outcomes. The present study, therefore, will focus on both how the job choice decision is made and on the effects of the choice on later attitudes and beliefs.

\section{METHODOLOGY}

\section{Procedure}

Students at 24 universities were contacted and asked if they would participate in a study of careers in public accounting. The universities involved are located in all parts of the country and vary widely in academic prestige. They are, however, all major producers of Certified Public Accountants (CPAs) and because of this most of the large CPA firms send interviewers to these schools. Participants were informed that a number of public accounting firms as well as two major professional accounting associations (American Institute of Certified Public Accountants; American Accounting Association) were sponsoring a study and that all students who were interested in a career in public accounting were invited to sign up for the study. Those students who signed up for the study were asked to complete an extensive questionnaire and the Strong Vocational Interest Blank in the autumn terms of their last year in school. This meant that they completed the questionnaire prior to 
their contacts with firm recruiters and prior to their selecting a job. Where possible, the questionnaires were completed in the presence of one of the researchers. At this time, the subjects were asked to place their names on the questionnaire so they could be contacted later and the confidentiality of individual data was stressed. The students were also promised feedback from the study and at a later time they did receive it.

The students were mailed a second questionnaire near the end of their spring term in school. At this time they were asked to complete the California Psychological Inventory. By this time the CPA firms have normally completed their hiring for the year. All subjects were mailed a third questionnaire after they had been employed for approximately one year.

\section{Questionnaire Measures}

Of the three questionnaires that were administered as part of the study, the first (pre-job application) questionnaire was the longest and contained a number of sections which are relevant for the present study.

Demographic data. A number of demographic and biographical data questions were included. These included basic information items (e.g., sex and age), work experience items, educational performance items, and childhood background items (e.g., family social economic status).

Attitudinal data. Firm attractiveness and $E \rightarrow P$ expectancy were measured by the following items:

1. The names of eleven large Public Accounting firms are listed below. Would you please rate them down the left-side column in terms of how desirable you think it would be to work for each one of them. Please use the following numbering system in order to indicate how desirable you consider working for each firm to be. Place the number that indicates your feeling on the line to the left of each firm. If you are not familiar with any of the list firms, place an $\mathrm{x}$ opposite the firm name.

1. Extremely desirable

2. Very desirable

3. Desirable

4. Moderately desirable

5. Neutral

6. Moderately undesirable

7. Undesirable

8. Very undesirable

9. Extremely undesirable (List of firms) 
2. Now we would like you to go back over the firms and rate them down the right side column in terms of how likely you think it is they would make you a job offer if you were to interview with them. Use the scale below. If, for example, you are confident you would get a job offer from Arthur Young \& Company if you interviewed with them, you would place a 5 on the line to the right of Arthur Young \& Company.

\begin{tabular}{|c|c|c|c|c|}
\hline 1 & 2 & 3 & 4 & 5 \\
\hline 1 & 1 & 1 & 1 & I \\
\hline $\begin{array}{l}\text { No } \\
\text { chance }\end{array}$ & $\begin{array}{l}\text { Slight } \\
\text { change }\end{array}$ & $\begin{array}{c}\text { Moderately } \\
\text { likely }\end{array}$ & $\begin{array}{l}\text { Very } \\
\text { likely }\end{array}$ & $\begin{array}{c}\text { Extremely } \\
\text { likely }\end{array}$ \\
\hline
\end{tabular}

The $\mathrm{P} \rightarrow \mathrm{O}$ expectancies for the firms were measured by the following items:

1. Now we would like you to rate six of the Public Accounting firms in terms of how much opportunity there would be for attaining eleven factors. Would you please choose six of the firms to rate and write their initials in the blanks numbered 1-6 below. Try to pick some firms you expect to interview and some you don't. Rate them in terms of how much opportunity they provide using the following scale. Be sure to rate six firms on all eleven factors so that all the blanks are complete.

\begin{tabular}{ccccc}
1 & 2 & 3 & 4 & 5 \\
\hline $\begin{array}{c}\text { No } \\
\text { opportunity }\end{array}$ & $\begin{array}{c}\text { Slight } \\
\text { opportunity }\end{array}$ & $\begin{array}{c}\text { Some } \\
\text { opportunity }\end{array}$ & $\begin{array}{c}\text { Considerable } \\
\text { opportunity }\end{array}$ & $\begin{array}{c}\text { Excellent } \\
\text { opportunity }\end{array}$
\end{tabular}

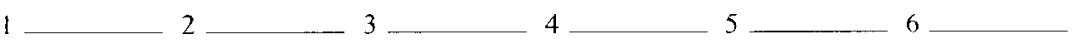

(The following outcomes were listed: Warm personal relationships at work, Work that uses your education and abilities, Acquire prestige in the eyes of your accounting colleagues, Feeling of helping people, Promotion and advancement, Interesting and challenging work, High pay, Personal growth and development, Feelings of competence and self-esteem, High job security, Freedom to determine own work methods and procedures)

The valence or attractiveness of each of the eleven outcomes of work was measured by one item which asked the subject to rate the outcomes on a five-point scale ( 1 not desirable to 5 extremely desirable). 
TABLE 1

Major Variables Measured with Each Questionnaire

\begin{tabular}{cccc}
\hline \multicolumn{1}{c}{ Variable } & Pre-application & Post job choice & $\begin{array}{c}\text { After one year of } \\
\text { employment }\end{array}$ \\
\hline $\begin{array}{c}\text { Firm attractiveness } \\
\text { (all 11 firms) }\end{array}$ & Yes & Yes & Yes \\
$\begin{array}{l}\mathrm{P} \rightarrow \text { O expectancies } \\
\mathrm{E} \rightarrow \text { P Expectancies }\end{array}$ & Yes & Yes & No \\
\hline
\end{tabular}

Additional questionnaires. The second questionnaire (post-job choice) again asked the subjects to rate the desirability of working for each of the firms and it repeated the question concerned with $\mathrm{P} \rightarrow \mathrm{O}$ expectancies. It also asked the students to indicate which firms they applied to for jobs, which firms offered them jobs, and which job if any they accepted. The third questionnaire (after one year of employment) asked the students to again rate the desirability of working for each of the eleven firms. Table 1 shows the data which were collected at each point in the study.

\section{Sample}

A total of 711 students completed the first questionnaire of which 515 were undergraduates and 196 were graduate students. The second questionnaire was completed by 431 students, of which 201 took accounting jobs with CPA firms and remained in the sample. One hundred ninety seven of the 201 returned the third questionnaire. Eleven percent of the original sample were women and the average age of the sample was 23.4 yr. Over $90 \%$ of the students were accounting majors and approximately $40 \%$ of them had some accounting related work experience. The majority $(66 \%)$ of the students came from families where the father did not graduate from college. However, only $27 \%$ of the students came from homes where the father was a nonmanagement production or service worker.

\section{RESULTS}

The prediction of expectancy theory that the attractiveness of a job is a function of $[(\mathrm{P} \rightarrow \mathrm{O})(\mathrm{V})]$ was tested by computing how each individual rated the firms on the first questionnaire. The resulting composite score for each firm was then correlated with the rating of firm attractiveness giving a correlation of $.34(p<.01)$ when all firms were considered. In order to determine if multiplying by the valence (V) measures was increasing the correlation, the sum of the $\mathrm{P} \rightarrow \mathrm{O}$ scores alone was correlated with the firm attractiveness rating and this yielded a correlation of $.40(p<.01)$. Thus, the multiplication operation did not increase 
the ability of the summed $\mathrm{P} \rightarrow \mathrm{O}$ expectancies to predict firm attractiveness. This analysis was repeated using the second questionnaire data with similar results.

The predictions concerned with which jobs would be applied for were tested by correlating (using biserial correlation techniques) the data from the pre-application questionnaire with the data obtained later on which jobs the individuals actually interviewed for. Pre-application firm valence was correlated $.48(p<.01)$ with the actual interview behavior of the individuals indicating that individuals did apply for those jobs which they saw as more attractive. The $\mathrm{E} \rightarrow \mathrm{P}$ measure correlated .18 $(p<.01)$ with interview behavior indicating that there was a slight tendency for individuals to apply to those firms from which they thought they were more likely to receive job offers. A further analysis of these data showed that the low correlation was not due to a curvilinear relationship. The multiplicative combination of the $\mathrm{E} \rightarrow \mathrm{P}$ and attractiveness correlated $.40(p<.01)$ with job application behavior. Thus, the combination measure did not predict better than the attractiveness measure alone. Table 2 shows the distributions of the firm attractiveness ratings. As can be seen the ratings are distributed in the form of a rough normal distribution. It also shows the nature of the relationship between the ratings and the tendency of the students to interview the firms. This relationship is generally linear although there is a slight tendency for the least attractive rating to produce a higher than expected interview rate. The data show that there is a clear tendency for job attractiveness to be related to job choice.

Table 3 also presents an analysis of the actual job choice behavior of those individuals who had two or more job offers. As can be seen from

TABLE 2

EFFECTS OF FIRM VALENCE

\begin{tabular}{lccc}
\hline \multicolumn{1}{c}{ Valence level } & $\begin{array}{c}\text { Percent of } \\
\text { ratings }\end{array}$ & $\begin{array}{c}\text { Percent of firms } \\
\text { interviewed }\end{array}$ & $\begin{array}{c}\text { Percent of offers accepted } \\
\text { for individuals with } \\
\text { multiple offers }\end{array}$ \\
\hline 1 (Extremely desirable) & 14 & 75 & 46 \\
2 & 15 & 65 & 31 \\
3 & 20 & 60 & 21 \\
4 & 13 & 52 & 21 \\
5 & 18 & 30 & 26 \\
6 & 7 & 47 & $*$ \\
7 & 6 & 30 & $*$ \\
8 & 2 & 29 & $*$ \\
9 (Extremely undesirable) & 4 & 49 & \\
\hline
\end{tabular}

$* N<5$. 
TABLE 3

Decision Behavior of Individuals with Multiple Offers

\begin{tabular}{lcc}
\hline & $\begin{array}{c}\text { Pre-application } \\
\text { valence }\end{array}$ & $\begin{array}{c}\text { Post-job choice } \\
\text { valence }\end{array}$ \\
\hline Number choosing highest valence firm & 71 & 101 \\
Number choosing lower valence firm & 18 & 1 \\
Number choosing firms with missing & & \\
$\quad$ valence data & 20 & 7 \\
Total & 109 & 109 \\
Hit rate & $80 \%$ & $99 \%$ \\
& $(71 / 89)$ & $(101 / 102)$ \\
\hline
\end{tabular}

the data, $80 \%$ of them took the job which had the highest attractiveness before they began interviewing $(p<.01$ when compared with a $50 \%$ or chance hit rate if everyone only had two job offers). The table also shows that $99 \%$ state after they had taken the job that it was their most attractive job offer $(p<.01$ when compared with $50 \%)$. The increase from $80 \%$ to $99 \%$ is significant $(p<.01)$.

An analysis of the attractiveness scores for all the firms showed that they decreased from the pre-application to post-job choice questionnaire (3.2 vs 3.8, $p<.01, t=16.2$ ) and that they were still lower one year later when the post-employment questionnaire was administered (4.4, $p<.01, t=11.2$ in comparison to post-job choice scores). An analysis of the $\mathrm{P} \rightarrow \mathrm{O}$ expectancies showed similar results. A separate analysis was made to determine how the attractiveness scores were affected by an individual deciding to go to work for a particular firm. When only those attractiveness ratings that involved an individual rating the firm whose offer he or she accepted were compared there was a significant increase in the attractiveness ratings (pre-application 2.6, post-job choice $1.3, p<.01, t=4.5$ ). When these same subjects were tested after a year of work, the rated attractiveness of their chosen firm had decreased somewhat $(1.8, p<.10, t=1.8)$ although it was still higher than it had been at the time of the first questionnaire.

Individuals who rejected offers from firms rated the attractiveness of the rejected firms lower after they had decided to decline the offer than they had rated them before they applied for employment ( 2.8 preapplication and 3.3 post-application, $p<.01, t=3.2$ ). The ratings of the rejected firms were even lower after they had worked one year (3.9, $p<.01, t=3.1$ when compared with the post-application score of 3.3). Thus, after accepting employment with a firm, individuals rated the attractiveness of working for other firms lower and the attractiveness of working for the chosen firm higher indicating that job choice influenced attitudes toward the firms. 


\section{DISCUSSION}

The present study offers partial support for the prediction that the attractiveness of a job is equal to $\Sigma[(\mathrm{P} \rightarrow \mathrm{O})(\mathrm{V})]$. The data shows that $\mathrm{P} \rightarrow \mathrm{O}$ is a significant predictor of job attractiveness, but that the use of V does not improve it. Holstron and Beech (1973), Vroom (1966), and Wanous (1972) did not separately correlate $\Sigma(P \rightarrow O)$ and $\Sigma[(\mathrm{P} \rightarrow \mathrm{O})(\mathrm{V})]$ with job attractiveness and thus it is impossible to tell if their data also show that multiplying by the $\mathrm{V}$ measures fails to increase predictability. Mitchell and Knudsen (1973) and Sheard (1970) do report separate correlations and they, too, found that the multiplicative operation did not increase predictability. A number of studies concerned with job performance (see Lawler \& Suttle, 1973) have alse failed to find support for the multiplicative use of $\mathrm{V}$. In this study the $\mathrm{V}$ ratings for the eleven factors showed very little variance among individuals as they were all rated as very attractive factors. When this is true it is hard for a multiplicative procedure to add to prediction particularly when the items are not measured on a ratio scale (Schmidt, 1973). In addition, the $\mathrm{P} \rightarrow \mathrm{O}$ measure might be influenced by $\mathrm{V}$ so that multiplication is redundant. Because of this it is not clear whether its failure to increase prediction is caused by measurement problems or whether it reflects a problem with the theory. It is clear that multiplying $\mathrm{P} \rightarrow \mathrm{O}$ measures by the kind of rating measures of attractiveness which were used in the present study does not increase the predictive ability of $\mathrm{P} \rightarrow \mathrm{O}$ measures.

The best predictor of which jobs the student applied for were the attractiveness measures. In fact, the predictions were surprisingly good given that the ratings were made several months before job interviews began and given that many things can interfere with an individual from actually applying for a job. The $\mathrm{E} \rightarrow \mathrm{P}$ measure also predicted whether individuals would apply for jobs but not well. Finally, combining $E \rightarrow P$ and job attractiveness multiplicatively did not lead to an increase in prediction. Again a prediction of expectancy theory which involves the multiplicative combination of data is not supported and again it is not clear why the prediction was not supported. Job interviewing does not fit the kind of choice situation that expectancy theory is concerned with since it does not involve mutually exclusive choices. Further strategies that were not measured may have influenced which jobs the students applied for. A measurement problem may also have been responsible since there was little between firm variance in the $\mathrm{E} \rightarrow \mathrm{P}$ measures and they were not ratio scales. Thus, the failure of the multiplicative combination to improve prediction is not a clear refutation of expectancy theory. Still it is apparent that the kinds of multiplicative combinations 
which are suggested by expectancy theory simply are not useful when conventional attitude measures are used and the object is to predict a specified attitude or behavior.

The data do show that job attractiveness ratings are good predictors of actual job choice. This is rather surprising since most of the attractiveness ratings were made six months or more before the students actually decided which job to take. Apparently the actual interview process did little to change the relative attractiveness of working for the different firms. There is reason to believe that these students knew a considerable amount about the firms before they started interviewing. Many had previous work experience and as a general rule, accounting students are exposed to a lot if information about CPA firms during their education (Sorensen, Rhode \& Lawler, 1973). Their views probably were well formed before the whole recruitment process began and because of this the recruitment process had little impact on them. One implication of this finding is that CPA firm "image" does make a difference in terms of behavior.

The data provide support for the existence of a post-decisional dissonance effect. The attractiveness of the chosen firms shows evidence of going up while the attractiveness of the other firms goes down as would be predicted by the theory. This was also found by Vroom (1966) in his earlier study. The finding of enhanced attractiveness for the chosen firm is particularly interesting since during the time between the first and second data collections the attractiveness of all firms went down. The later finding might indicate that the more the students found out about the firms the less attractive they were since the students had a lot of contact with the firms between the two surveys. It may also have been a dissonance effect that was produced by the students choosing to go to work for one of the firms. Given Vroom's finding of postdecision dissonance in the time period between job offer and job choice, this was a likely cause of part of the reduction in the attractiveness scores. However, to definitely establish this interpretation, data would also have to have been collected at a point that fell before the job choice decision but after the person had gone through the job application process:

The present study is in agreement with those previous studies which have shown that employees' feelings toward their organizations become more negative during their initial period of employment. In fact, the data show that these students' attitudes toward working in all CPA firms decreased after they had worked for a period of a little over a year. As Vroom and Deci (1971) note, this probably is caused by a failure of the jobs to meet the high expectations of the students.

The results showing changes in firm attractiveness scores as a result of experience and post-decision dissonance are particularly interesting 
when they are considered together with expectancy theory. Most versions of expectancy theory have not specified what factors influence such variables as $\mathrm{P} \rightarrow \mathrm{O}$ beliefs. The present data suggest that attempts to do this must look at the objective characteristics of the environment and the nature of the person's experience and past behavior. In other words, although Wanous (1972) found objective accuracy in students' perceptions of salaries, people's beliefs about the environment will not necessarily reflect the objective environment accurately nor will their behavior be optimal in terms of it. On the other hand, the data do support the prediction of expectancy theory that people will behave rationally with respect to the environment as they perceive it. This is evidenced by the frequency with which individuals chose the job they found to be most attractive.

The post-decision data suggest that individuals need to feel rational since they brought their perceptions into line with their behavior. This brings the discussion back full circle to the point that firm attractiveness is a crucial determinant of behavior. Although the $P \rightarrow \mathrm{O}$ data showed that attractiveness is partially determined by the rewards which the firms offer, this does not seem to account for all the variance in it. It would seem to be important to understand more about what else determines firm attractiveness since firm image, rather than what happens during the selection process, seems to be the major determinant of job application and job choice behavior.

The present study provides a particularly clear answer to the traditional question of whether attitudes determine behavior or behavior determines attitudes. It shows that attitudes can be both a cause of behavior and a consequence of behavior. The finding that attractiveness influences choice points to the ability of attitudes to cause behavior while the finding of attitude change as a result of job choice illustrates how behavior can cause attitudes to change.

\section{REFERENCES}

Atkinson, J. W. An introduction to motivation. Princeton, NJ: Van Nostrand, 1964. Festinger, L. A theory of cognitive dissonance. Evanston, IL: Row, Peterson, 1957. Holstron, V. L., \& BeEch, L. R. Subjective expected utility and career preferences. Organizational Behavior and Human Performance, 1973, 10, 201-207.

LAWLER, E. E. III. Motivation in work organizations. Monterey, CA: Brooks/Cole, 1973.

LAWLER, E E., \& Suttle, J. Lloyd. Expectancy theory and job behavior. Organizational Behavior and Human Performance, 1973, 9, 482-503.

Mitchell, T. R., \& KNUdSEN, B. W. Instrumentality theory predictions of students' attitudes toward business and their choice of business as an occupation. Academy of Management Journal, 1973, 16, 41-51.

SCHMIDT, F. L. Implications of a measurement problem for expectancy theory research. Organizational Behavior and Human Performance, 1973, 10, 243-251. 
SHEARD, J. L. Intrasubject prediction of preferences for organizational types. Journal of Applied Psychology, 1970, 54, 248-252.

Sorensen, J. E., Rhode, J. G., \& LAwler, E. E. The generation gap in public accounting. Journal of Accountancy, 1973, 136, 42-50.

SUPER, D. The psychology of careers. New York: Harper \& Brothers, 1957.

Super, D. E. \& BoHN, M. I. Occupational psychology. Belmont, CA: Wadsworth, 1970.

Vroom, V. H. Work and motivation. New York: J Wiley, 1964.

Vroom, V. H. Organizational Choice: A study of pre- and post-decision processes. Organizational Behavior and Human Performance, 1966, 1, 212-225.

Vroom, V. H. \& Deci, E. L. The stability of post-decision dissonance: A follow-up study of the job attitudes of business school graduates. Organizational Behavior and Human Performance, 1971, 6, 36-49.

WALSTER, E. The temporal sequences of post-decision processes. In L. Festinger, V. Allen et al. (Eds.), Conflict, decision, and dissonance. Stanford, CA: Stanford University Press, 1964, 112-128.

Wanous, J. P. Occupational preferences: Perceptions of valence and instrumentality and objective data, Journal of Applied Psychology, 1972, 56, 152-155.

Received: May 22, 1974 